Research Article

\title{
Character Association and their Contributions in Yield of Brassica juncea L.
}

\section{Huma Qamar', Mariam Hassan', Muhammad Zubair ${ }^{1 *}$, Adnan Arshad², Muhammad Qusain Saeed Muhammad Umar ${ }^{3}$, Sundas Shahzad ${ }^{1}$, Tariq Mahmood ${ }^{1}$ and Muhammad Aftab ${ }^{1}$}

\begin{abstract}
${ }^{1}$ Directorate of Oilseeds, Ayub Agriculture Research Institute, Jhang Road, Faisalabad, Pakistan; ${ }^{2}$ College of Resources and Environmental Science, China Agricultural University, Beijing, 100193, China; ${ }^{3}$ Department of Plant Breeding and Genetics, University of Agriculture, Faisalabad, Pakistan.
\end{abstract}

\begin{abstract}
Pakistan spends a major part of expenditure on import of the edible oil owing to significant rise in demand. Main aim of the study was to analyze the 18 genotypes of Brassica juncea L. for correlation and their path co-efficient analysis. Mean square for five traits was constructed which was highly significant except plant height. Correlation in plant's height and branches, days required for flowering and days required for maturity was positive at genotypic as well as phenotypic levels. Correlation between numbers of branches and days required for flowering was positive, while negative association of branches' number was observed with days required for maturity and the obtained yield of a plant. Positive association was expressed between days required for flowering and days required for maturity. Negative association was observed in days required for flowering and the obtained yield from a plant. Positive correlation was observed in days required for maturity and the obtained yield from a plant. The direct effect of plant's height on obtained yield was positive and indirect effects through days required for flowering was positive and the indirect negative effects were contributed through branches' numbers $(-5.54)$ and days required for maturity (12.27). Number of Branches have negative direct effect on the obtained plant's yield. Indirect effects posed by plant's height, days required for flowering and days required for maturity were positive. The present study shows that the plant's height is positively correlated with the other assessed traits and these can widely be used as priority for selecting the genotypes with higher yield.

Received | April 08, 2020; Accepted | June 25, 2021; Published | July 31, 2021

*Correspondence | Muhammad Zubair, Directorate of Oilseeds, Ayub Agriculture Research Institute, Jhang Road, Faisalabad, Pakistan; Email: chzubair92@gmail.com

Citation | Qamar, H., M. Hassan, M. Zubair, A. Arshad, M.Q. Saeed, M. Umar, S. Shahzad, T. Mahmood and M. Aftab. 2021. Character association and their contributions in yield of Brassica juncea L. Pakistan Journal of Agricultural Research, 34(3): 643-647.

DOI | https://dx.doi.org/10.17582/journal.pjar/2021/34.3.643.647

Keywords | Correlation, Path analysis, Morphological traits, Selection, Seed yield
\end{abstract}

\section{Introduction}

$\mathrm{E}$ conomy of Pakistan is primarily based on agriculture, but the gap between consumption and production increases every year (Aftab et al., 2020). In Pakistan, per capita oil consumption has been tremendously increased owing to the rapid increase in population. Domestically, $17 \%$ oil is produced to fulfill the domestic needs, and the remaining $83 \%$ is imported at the cost of Rs. 192.203 billion (US \$ 1.455 billion) to meet national edible oil requirements. Mustard and rapeseed are grown on about 263 thousand hectares and its production is 225 thousand tonnes. After cottonseed, mustard and rapeseed possess major share in domestic vegetable oil production (GoP, 2018-19). Many newly evolved Brassica cultivars contain $40-47 \%$ of oil content while contributing $32 \%$ in domestic edible oil production. 
So, in order to meet the national needs of edible oil, enhancing the production potential of oilseed crops; especially Brassica is need of the hour. Brassica juncea is consumed as vegetable e.g. salads, salad greens, condiments and medicinally. In sub-continent, its main purpose of cultivation is edible oil irrespective of other uses i.e. salad, medicine, and condiments (Anyaoha et al., 2015).

B. juncea enjoys wide adaptability and as a result, it is cultivated on a large scale in developing as well as in developed countries as oilseed crop in hot and dry areas, pod shattering, less susceptibility to diseases and comparatively higher oil contents (approximately up to 44\% (Stoutjesdijk et al., 2000; Pandey et al., 2013). In Pakistan, it is generally known as mustard which possesses higher levels of erucic acid, and glucosinolates are found in oil and in the meal, respectively. Mustard requires less quantity of inputs but enjoys wider adaptability. It is cultivated in irrigated as well as in rainfed areas of Pakistan. It is stated that better-quality varieties of Brassica have high production potential of $2500 \mathrm{~kg} / \mathrm{ha}$ which shows that 2-3 times rise in average yield can be achieved by selection of heigh yielding genotypes (Khan et al., 2006).

Yield is a multifaceted and quantitatively inherited character which is determined by various characters (Tuncturk and Ciftci, 2007). Performance of germplasm having objective traits to increase production and improve the human nutrition is very important in the development of new variety (Anyaoha et al., 2015). Successful of breeding program is determined by the genetic variation in germplasm. Present variation in germplasm is not sufficient to fulfill the requirements. Yield is influenced by environmental instabilities and secondary traits e. g. branches on a plant, seeds on siliques, main shoot length and weight of one thousand seeds (Dipti and Piryanaka, 2016). Thus, the correlation among yields and yield contributor traits help in crop improvement. This phenomenon measures the degree of association between the two traits (Steel and Torrie, 1984). It is necessary to know the role of various components of yield and their mutual correlation with other independent traits. Path analysis further interprets the link of these yield contributing characters along with yield for their direct or indirect impact via other component characters (Ahmed and Kamaluddin, 2013). The present study was conducted to study the association between traits and their contribution to yield among promising genotypes for developing high yielding mustard varieties.

\section{Materials and Methods}

The experiment was conducted in Rabi season in the year-2016-17 at Oilseeds Research Institute (ORI), Faisalabad. Seventeen different genotypes; RBJ-14017, RBJ-15012, RBJ-15013, RBJ-15017, RBJ-15018, RBJ-16001, RBJ-16004, RBJ-16006, RBJ-16007, RBJ-16008, RBJ-16010, RBJ-16012, RBJ-16017, RBJ-16018, RBJ-16019, RBJ-16020, RBJ-15786 and one approved variety; Super Raya were sown at research area of respective institute. Randomized Complete Block Design (RCBD) along with three replicates was adopted. Four rows; each 6-meter-long of each entry were sown. Row to Row spacing and Plant to Plant spacing were maintained at $45 \mathrm{~cm}$ and $15 \mathrm{~cm}$, respectively. Fertilizer, NPK (Kg/ ha) 75:75:0 were provided during land preparation. Irrigation was provided at seedling, flowering, silique formation, and seed formation stages. Weeds, insect pests and diseases were managed as per requirement.

\section{Morphological parameters}

Five different plants from each line were selected on the basis of good phenotypic appearance. Parameters regarding days taken for flowering, days taken for maturity, plant height, number of branches, silique length, and seeds per siliqua were recorded.

\section{Statistical data analysis}

Combined analysis of variance (ANOVA) was constructed while replications and location effects were considered as random, but genotypes were fixed variable as recommended by Steel and Torrie (1980). Characters' impacts were found by using correlation and path coefficients. Correlation and path coefficients were calculated by using TARPOPGEN Statistical Computer Program.

\section{Results and Discussion}

The presence of variation in germplasm is a primary requirement of valid selection among superior genotypes. The data showed a highly significant genotypic mean square of 18 genotypes for five traits except for plant height (Table 1).

Genotype RBJ-16018 had the higher number on plant 
branches (10) and the height of a plant $(236.33 \mathrm{~cm})$. Genotype RBJ-16012 showed maximum seed yield (1300 g). Genotype RBJ-16010 took maximum days for flowering (78 days) while genotypes RBJ-16017 and RBJ-16018 showed early maturity (149 days). This variability in phenotypic appearance was assessed for all characters aiming that these characters possess potential for their possible use in the development of new high yielding mustard varieties.

Table 1: Mean values for different yield related traits of Brassica juncea L. genotypes during Rabi 2016-17.

\begin{tabular}{|c|c|c|c|c|c|}
\hline Genotypes & $\begin{array}{l}\text { Branch- } \\
\text { es/plant }\end{array}$ & $\begin{array}{l}\text { Plant } \\
\text { height } \\
(\mathrm{cm})\end{array}$ & $\begin{array}{l}\text { Yield/ } \\
\text { plant (g) }\end{array}$ & $\begin{array}{l}\text { Days to } \\
\text { flower- } \\
\text { ing }\end{array}$ & $\begin{array}{l}\text { Days to } \\
\text { maturity }\end{array}$ \\
\hline RBJ-14017 & 9 & 220.07 & 1158.33 & 69 & 151 \\
\hline RBJ-15012 & 9 & 207.6 & 900 & 70 & 150 \\
\hline RBJ-15013 & 8 & 218.73 & 1033.33 & 69 & 152 \\
\hline RBJ-15017 & 8 & 233.73 & 1016.67 & 76 & 154 \\
\hline RBJ-15018 & 8 & 223.53 & 1100 & 71 & 153 \\
\hline RBJ-16001 & 9 & 199.73 & 950 & 66 & 150 \\
\hline RBJ-16004 & 10 & 209.27 & 1116.67 & 76 & 151 \\
\hline RBJ-16006 & 8 & 223.13 & 863.33 & 71 & 152 \\
\hline RBJ-16007 & 9 & 222.47 & 1206.67 & 67 & 151 \\
\hline RBJ-16008 & 10 & 217.53 & 975 & 68 & 151 \\
\hline RBJ-16010 & 9 & 228.27 & 860 & 78 & 153 \\
\hline RBJ-16012 & 9 & 207.07 & 1300 & 74 & 153 \\
\hline RBJ-16017 & 9 & 213.87 & 916.67 & 66 & 149 \\
\hline RBJ-16018 & 10 & 236.33 & 1000 & 73 & 149 \\
\hline RBJ-16019 & 9 & 227.53 & 966.67 & 75 & 154 \\
\hline RBJ-16020 & 9 & 219.13 & 1016.67 & 74 & 154 \\
\hline RBJ-15786 & 8 & 204.73 & 1450 & 66 & 152 \\
\hline Super Raya & 7 & 191.93 & 1066.67 & 62 & 152 \\
\hline $\begin{array}{l}\text { Mean square } \\
\text { (Genotypes) }\end{array}$ & $1.35185^{* *}$ & $415.17^{*}$ & $71434^{* * *}$ & $57.914^{* * *}$ & $8.5969^{* *}$ \\
\hline
\end{tabular}

significant $(P<0.05)$; : bighly significant $(P<0.01)$; significant $(P<0.001)$.

Genotypic and phenotypic variance for various characters have been presented in (Table 2), which indicate that plant height $(69.68244 \mathrm{~cm}, 275.80044$ $\mathrm{cm})$, yield per plant $(22185.72985 \mathrm{~g}, 27062.7451$ g) and days to flowering (17.87037 days, 22.1732 days) have maximum values. Results revealed that the presence of high amount of genetic variability indicates chances of improvement in these characters. The Phenotypic variance was observed higher, which indicated that abiotic factors have a significant role in the expression of characters. High heritability $\left(\mathrm{h}^{2}\right.$ в.S ) was also reported in yield per plant $(0.81979 \mathrm{~g})$ besides days taken to flowering (0.80594).

\section{Correlation analysis}

Genotypic and phenotypic correlations, were constructed, and all possible pair-wise combinations for traits were made (Table 3). Correlation in plant height and branches, days for flowering, and days for maturity were found positive at both levels. Negative and non-significant association with yield was found at both levels, which concluded that the height and yield of a plant are inversely proportional to each other. Number of branches is directly proportional to the days taken to flowering and while these are inversely proportional with days required for maturity and yield of a plant. Significant association was found in days required for flowering and days to maturity, while non-significant association was observed in days required for flowering and yield of a plant which indicates that early flowering gives higher yield. Days required for maturity are positively associated with the yield of a plant, which supported the claim that the more number of the days for maturity, the higher will be yield obtained per plant.

\section{Path coefficient analysis (PCA)}

PCA is a good tool to find the direct and indirect sources for correlations. Findings of the present study are mentioned in Table 4. The height of plants has directly positive impact on obtained yield, and it exhibited a path-coefficient value of 3.57. Indirect effects through days required for flowering (13.71) was positive, while indirect negative influence was contributed by branches $(-5.54)$ and days required for maturity (12.27). Plant height had a direct positive impact, which favors the claim that direct selection would be much effective when aimed at high yield. Table 4 also represents that the number of branches

Table 2: Different morphological characters for yield in Brassica juncea L. genotypes during Rabi 2016-17.

\begin{tabular}{|c|c|c|c|c|c|}
\hline Genetic parameters & Branches/plant & t Plant height (cm) & Yield/plant (g) & Days to flowering & Days to maturity \\
\hline Genotypic variance & 0.30841 & 69.68244 & 22185.72985 & 17.87037 & 2.01089 \\
\hline Phenotypic variance & 0.73503 & 275.80044 & 27062.7451 & 22.1732 & 4.57516 \\
\hline Heritability in broad sense $\left(\mathrm{h}^{2}{ }_{\text {B.S }}\right.$ & 0.41959 & 0.25266 & 0.81979 & 0.80594 & 0.43952 \\
\hline
\end{tabular}

September 2021 | Volume 34 | Issue 3 | Page 645 
on a plant had an inverse influence on obtained plant yield. While indirect effects by height of plant (1.16 $\mathrm{cm})$, days required for flowering (5.11), and days required for maturity (10.36) were positive. In this case, the direct selection for the number of branches on a plant will surely decrease the obtained yield. However, indirect selection through plant height, days required for maturity, and days required for flowering might be beneficial.

Table 3: Correlation in morphological characters for yield in Brassica juncea L.

$\begin{array}{llllll}\text { Traits } & & \text { Branches } & \begin{array}{l}\text { Days to } \\ \text { flowering }\end{array} & \begin{array}{l}\text { Days to } \\ \text { maturity }\end{array} & \text { Yield } \\ \text { Plant } & \text { GC } & 0.326 & 0.880 & 0.595 & -0.534 \\ \text { height } & \text { PC } & 0.097 & 0.441 & 0.076 & -0.099 \\ \text { Branches } & \text { GC } & & 0.328 & -0.502 & -0.316 \\ & \text { PC } & & 0.158 & -0.196 & -0.152 \\ \text { Days to } & \text { GC } & & & 0.648 & -0.219 \\ \text { flowering } & \text { PC } & & & 0.468 & -0.227 \\ \text { Days to } & \text { GC } & & & & 0.129 \\ \text { Maturity } & \text { PC } & & & & 0.050\end{array}$

GC: Genotypic correlation; PC: Phenotypic correlation.

Table 4: Direct and indirect effect among yield related parameters.

\begin{tabular}{|lllll} 
Traits & $\begin{array}{l}\text { Plant } \\
\text { height }\end{array}$ & Branches & $\begin{array}{l}\text { Days to } \\
\text { flowering }\end{array}$ & $\begin{array}{l}\text { Days to } \\
\text { maturity }\end{array}$ \\
Plant height $(\mathrm{cm})$ & 3.57 & -5.54 & 13.71 & -12.27 \\
Branches & 1.16 & -16.96 & 5.11 & 10.36 \\
Days to flowering & 1.16 & -5.56 & 15.58 & -13.37 \\
Days to maturity & 2.12 & 8.52 & 10.1 & -20.62
\end{tabular}

The days required for flowering have a significant impact (15.58) over obtained yield. While, the negative indirect effects measured in branches $(-5.56)$, days required for maturity (-20.62) and plant's height had positive indirect effects. High positively direct impacts suggested that days to flowering is a significant component of yield. Days taken to maturity (-20-62) had directly inverse influence on yield obtained by a plant While indirectly positive effects were found in plant height (2.12), days required for flowering (8.52) and days required for maturity (10.1). This is crystal clear from the above facts that although direct effect of days taken to maturity had negative effect, but, some of the other traits such as plant's height, branches and days to flowering exert positive effects which increase yield.
The data obtained in the present study claims that the plant's height is positively correlated at the genotypic and phenotypic levels, with days required for maturity as witnessed by (Doddabhimappa et al., 2009). They are also of the view that the branches on a plant do not have a significant relationship with days required for flowering as discovered by the present study, but, the relationship of the days required for maturity is contrary to our results. Plant height has a nonsignificant correlation with the number of branches on a plant. But, according to the findings of this study, plant height and branches were positively associated phenotypically and genotypically. Anyaoha et al. (2015) conform with our findings that days required for flowering expressed the highly positive correlation along with plant's height. Basalma (2011) reported that there is non-significant association of yield of a plant when associated with the number of branches as the findings of present study.

Seed yield is highly correlated with the number of branches on a plant at the genotypic and phenotypic levels. Seed weight is positively correlated with the harvest-index, duration of flowering, and the obtained yield which indicates that the significant improvement in seed weight improves the harvestindex resulting in more obtained yield. While, it is also reported that there is no correlation of flowering days with the plant's height, number of seeds on a silique and with the oil content. Plant's height shows a negative correlation with seeds on a silique and obtained seed yield (Ali et al., 2013).

The plant height had a direct positive impact on days required for maturity, as found in the present study. Path-coefficient analysis (PCA) represents that the yield associated traits, e.g. 50\% flowering, silique on main raceme and biological yield of a plant had direct positive impact on obtained seed yield. Dipti and Piryanka (2016) reported that branches positively exhibit phenotypic association with obtained yield, but in our results, number of branches expressed negative direct effect on plant's yield. The days required for maturity expressed directly positive impact on seed yield of a plant could not positively contribute to seed yield which is non-significant with obtained yield due to the majority of negative indirect effects similar to our result.

\section{Conclusions and Recommendations}

In our study, genotypic mean squares (MS) of 18 
genotypes regarding five traits were assessed, which was highly significant, excluding that trait of plant height, for which it was only significant. Association in plant height and number of branches on a plant, days required for flowering and maturity were positive at genotypic and phenotypic scale. Positive association was witnessed in branches and days required for flowering, flowering period and days required for maturity, days required for maturity and yield per plant. A negative association was found in the number of branches and days required for maturity, days required for flowering and the obtained yield per plant. The direct effect of plant's height on obtained yield was positive and in-direct effects through days required for flowering were positive, and the indirect effects of branches have negative value and days required for maturity had positive value. The numbers of branches directly represented negative impacts on obtained plant yield. On the other hand, indirect effect through plant height, days required for flowering, and days required for maturity were significantly positive. These findings will be used in the development of new cultivars of Brassica juncea with better yield.

\section{Novelty Statement}

This study paves way for selecting specific plant traits as basis of selection for higher yield.

\section{Author's Contribution}

HQ and MH: Designed the study.

MQS and MU: Conducted the study.

SS and TM: Supervised the study.

AA and MA: Statistically analyzed the data.

MZ: Formatted and finalized the manuscript.

\section{Conflict of interests}

The authors have declared no conflict of interest.

\section{References}

Aftab, M., S. Fatima, H. Qamar, M. Hassan, M. Zubair, A. Arshad, T. Mahmood, S. Ali, S. Shahzad, M.R. Khurshid, M.K. Malik, A.M.U. Din, N.A. Maan and M. Ilyas. 2020. Study of morphological characters give an insight into the genetic variation present in Brassica napus L. Germplasm. L. Sci. J., 17(3): 56-61.

Ahmed, S. and Kamaluddin. 2013. Correlation and path analysis for agro-morphological traits in rajmash beans under Baramulla Kashmir region. Afr. J. Agric. Res., 8(18): 2027-2032. https://doi.org/10.5897/AJAR2012.0014

Ali, Y., F. Ullah, H. Rahman, A. Nasim, S.M. Azam and A. Khan. 2013. Heritability and correlation analysis for morphological and biochemical titsra in Brassica carinata. Sarhad J. Agric., 29(3): 359-369.

Anyaoha, C.O., U. Orkpeh and T.A. Fariyike. 2015. Morphological characterization and preliminary evaluation of four breeding lines of Brassica juncea (mustard seed) in Nigeria. Cont. J. Agric. Sci., 9(1): 8-13.

Basalma, D., 2011. The correlation and path analysis of yield and yield components of different winter rapeseed (Brassica napus sp. oleifera L.) cultivars. Res. J. Agric. Biol. Sci., 4(2): 120-125.

Dipti, V.C. and Priyanka. 2016. Correlation and path coefficient analysis for yields contributing parameters in indian mustard [Brassica juncea L. Czern and coss.]. Am. J. Pharm. Res., 6(2): 665-675.

Doddabhimappa, R., B.G. Gangapur,P.M.Prakash, R.L. Salimath, Ravikumar and M.S.L. Rao. 2009. Correlation and path analysis in Indian mustard (Brassica juncea L. Czern and Coss). Karn. J. Agric. Sci., 22(5): 971-977.

Government of Pakistan. 2018-19. Ministry of Finance. Economic Survey of Pakistan.

Khan, F.A., S. Ali, A. Shakeel, A. Saeed and G. Abbas. 2006. Genetic variability and genetic advance analysis for some morphological traits in Brassica napus L. J. Agric. Res., 44(2): 83-88.

Pandey, S., M. Kabdal and M.K. Tripathi. 2013. Study of inheritance of erucic acid in Indian mustard (Brassica juncea L. Czern and Coss). Oct. J. Biosci., 1: 77-84.

Steel, R.G. and J.H. Torrie. 1980. Principles and procedure of statistics. A biometrical approach. McGraw Hill Book Co., New York. pp.137-167. Stoutjesdijk, P.A., C. Hurlestone, S.P. Singh and A.G. Green. 2000. High oleic acid Australian Brassica napus and B.juncea varieties produced by co-suppression of endogenous $\Delta 12$-desaturases. Biochem. Soc. Trans., 28: 938-994. https://doi. org/10.1042/bst0280938

Tuncturk, M. and V. Ciftci. 2007. Relationships between yield and some yield components in rapeseed (Brassica napus ssp. oleifera L.) cultivars by using correlation and path analysis. Pak. J. Bot., 39(1): 81-84. 